\title{
THE CRITICAL PERIOD IN THE DEVELOPMENT OF THE INTESTINES
}

\author{
C. R. BARDEEN \\ From the Anatomical Laboratory, University of Wisconsin \\ ELEVEN Figures (FOUR PLATES)
}

In studying the variations of structure found in any part of the body it is of importance to distinguish the less variable from the more variable features. As a rule, the less variable features are associated with fundamental processes occurring early in ontogenetic development, the more variable features with processes of growth and differentiation occurring later in ontogenetic development. Thus while it is comparatively rare to have variation in the number of the digits, finger prints are specific for each individual.

In the development of the human intestines three fundamental loops are formed. First, the entero-colic which extends forward into the umbilical cord and is supplied by the superior mesenteric artery. Second, the gastro-duodenal, which projects to the right at the base of the entero-colic loop and is supplied chiefly by a branch of the coeliac artery. Third, the left colic which projects to the left at the base of the entero-colic loop and is supplied chiefly by the inferior mesenteric artery.

The entero-colic loop undergoes normally an elaborate development and gives rise to the distal part of the duodenum, the jejunum, ileum, caecum, ascending colon and the right half of the transverse colon. The center of the base of the mesentery of this loop is in the region of the origin of the omphalo-mesenteric or superior mesenteric artery from the aorta. This becomes fixed at an early period opposite the first lumbar vertebra and seldom varies in position. The loop itself shows frequent variations in development, some of a fundamental character, others slight. These will be discussed below. 
The gastro-duodenal loop is simple and seldom shows fundamental variations, although individual differences in form in the adult are frequent and well marked. Primitively it is of a simple $\mathrm{U}$ form, as may be seen in figures 1,3 and 5. Such variations as are found in the adult seem to be due in the main to variations in the position of the stomach and to variations in the development of the entero-colic loop (for instance, see figs. 10 and 11).

The left colic loop, although it begins its development considerably later than the other two primitive loops (in fetuses $30-40 \mathrm{~mm}$. long, figs. $3,4,5,6,7$ ) appears to be nearly as constant in formation. It is usually fixed at an early period in the vicinity of the left side of the left kidney. From it develop the left half of the transverse colon, the splenic flexure, the descending colon and the sigmoid colon. Even in cases in which the entero-colic loop shows marked abnormalities in development one usually finds the upper part of the descending colon in approximately normal position (see for instance, figs. 10 and 11). Aside from extremely teratological cases and cases of complete situs transversus I have found only one case clearly described in which the upper part of the descending colon did not lie in the vicinity of the left kidney. In this case, described by Koch, ${ }^{1}$ the colon extended in the middorsal line from the pelvis nearly to the transverse part of the duodenum and then bent toward the right side.

The relative constancy in the position of the upper part of the descending colon is probably, due to pressure exerted at an early period by the neighboring intestinal coils against the mesocolon of this portion of the gut (figs. 6 and 7). This part of the mesocolon is thus caused to be fused against the dorsal wall of the abdominal cavity. Proximal and distal to this region of attachment of the colon variations in the development and disposition of the colon arc frequent.

Figures 8 and 9 exhibit somewhat extreme variations in the development of the left colic loop above and below the region of early fixation. Above this region the splenic flexure has sent out a loop far to the right in front of the stomach, transverse colon

\footnotetext{
1 Die angeborenen ungewöhnlichen Lagen und Gestaltungen des menschlichen Darmes, Deut. Zeitschr. f. Chirurgie, Bd. 50, s. 1, 1898.
} 
and liver. Below this region the colon bends across the middorsal line to the right side of the body before descending into the pelvic cavity.

The entero-colic loop undergoes its early development in part in the umbilical cord, in part in the abdominal cavity. The umbilical part is finally withdrawn (in embryos about $40 \mathrm{~mm}$. long) into the right side of the abdominal cavity and subsequently undergoes considerable shifting before the conditions characteristic of the adult are reached. The more fundamental variation in the development of this loop have to do first, with the intraumbilical and intra-abdominal development of the loop preceding the withdrawal of the umbilical portion into the abdominal cavity and, second, with the process of withdrawal of the umbilical portion, the ultimate disposition of the various parts of the loop within the abdominal cavity and their subsequent development.

The development of the umbilical part of the loop has been most carefully studied by Mall, ${ }^{2}$ who has described the differentiation of three primary coils of the small intestines within the umbilical cord and their elaboration preceding withdrawal into the abdominal cavity. This development is illustrated in figures 1 , 2,3 and 4 which correspond essentially with figures of corresponding stages illustrated by Mall. There seems to be considerable regularity in the early development of this part of the intestines. Probably the conditions within the umbilical cord are fairly constant and there is little there to interfere with free development.

The active development of the entero-colic loop within the abdominal cavity, on the other hand, seems to take place under greater difficulties and to be subject to greater variation. It does not begin until the development of coils within the umbilical cord is well advanced and is relatively most active at the period immediately preceding and during the return of the umbilical coils into the abdominal cavity.

At this period the colon projects nearly straight forwards in the median plane from near the lower border of the stomach into

${ }^{2}$ Ueber die Entwickelung des menschlichen Darmes und seiner Lage beim Erwachsenen. His Archiv, 1897. 
the umbilical cord (fgs. 4, 5, 6, 7). This part of the colon, together with the superior mesenteric artery, which runs nearly parallel with it, and the mesentery which is thickened along the course of the artery, especially near the base, forms a stalk or skeletal support from which the mesentery of the small intestine seems to hang (fig. 7). The part of the mesentery of the free small intestines attached to the part of the umbilical stalk which extends or has extended into the umbilical cord may be looked upon as belonging to coils which have developed within the umbilical cord. The part of the mesentery of the free small intestines attached to the abdominal part of the umbilical stalk may be looked upon as belonging to the coils whichhave developed within the abdominal cavity.

The beginning of the development of the abdominal coils is marked by the projection of a duodeno-jejunal loop to the left beneath the umbilical stalk. In a $27 \mathrm{~mm}$. embryo (f.gs. 1, 2) this loop extends to the left of the median plane and at its distal extremity bends ventralwards (fig. 2). In a $35 \mathrm{~mm}$. embryo this duodeno-jejunal loop has begun to give rise to distinct jejunal coils (figs. 3, 4). These coils now develop very rapidly so that in a $40 \mathrm{~mm}$. embryo they approximate in extent the ileac coils in the umbilical cord (fgs. 5, 6, 7, coils on left side of umbilical stalk). Just before the jejunal coils begin their most rapid development the bursa omentalis becomes considerably distended (figs. 2, 4).

It is difficult to judge whether this distention is an active one which helps to create more space in the abdominal cavity on the left side, or a passive one due to a sudden increase in the space in the left abdominal cavity. At this period the spinal axis of the embryo in the lumbo-sacral region changes from ventral flexion to dorsal fexion. Whatever factors may be involved in this the result undoubtedly is to offer more space for intestinal development in the abdominal cavity. The steps in this latter process are, first, dilatation of the bursa omentalis; second, rapid development of jejunal coils in the left. abdominal cavity and a collapse of the previously swollen bursa omentalis, and, third, the return to the abdominal cavity of the ileac coils from the umbilical cord. The 
latter process is under way in the $40 \mathrm{~mm}$. embryo shown in figures 5,6 and 7 .

Normally the jejunal or abdominal coils of the small intestines develop simultaneously with the left colic loop, described above (figs. 3, 4, 5, 6, 7). That this coincident development is not constant is indicated by the numerous cases which have been described, in which, with an approximately normal disposition of the upper part of the descending colon, indicating a fairly normal early development of the colic loop, the proximal part of the small intestines has occupied a markedly abnormal position. In these cases, an excellent example of which is given by Strehl $^{3}$ and another by Huntington, ${ }^{4}$ the primitive duodeno-jejunal loop appears to be diverted from its usual course of development beneath the umbilical stalk and to have been forced to develop, in so far as development has taken place, on the proximal side of the stalk. In the illustration given by Huntington (fig. 10) the duodeno-jejunal loop appears in about the state of development normally found in embryos 24 to $28 \mathrm{~mm}$. long (figs. 1 and 2). In the illustration given by Broman (fig. 11) the duodeno-jejunal loop appears even less advanced in normal development. When the duodeno-jejunal loop fails to develop to the left beneath the umbilical stalk there appears in general to be a subsequent lack of development of the proximal part of the small intestines. In such cases the intestinal coils are probably in the main coils which have developed in the umbilical cord and then have returned to the abdominal cavity. It is probable that in these cases factors which normally leave room for the development of coils below and to the left of the umbilical stalk become inoperative. Possibly the pressure of the liver is greater than normal. Possibly the lower part of the trunk fails to expand as rapidly as normal.

In most of these cases the umbilical part of the colon fails to reach its usual position when the umbilical coils return to the abdominal cavity. Normally, as is well known, it swings across the ventral side of the loops of the small intestine in the left side

${ }^{3}$ Arch. f. klin. Chirurgie, Bd. 87, 1908, cited by Broman; Normale und abnorme Entwichlung des Mensehen, fig. 326, p. 380.

${ }^{4}$ Anatomy of the peritoneum and abdomen, fig. 121. 
of the abdominal cavity and comes to lie below the pyloric end of the stomach and the liver in the right hypochondriac region. The entero-colic loop viewed from in front thus undergoes torsion in a direction opposite to the movement of the hands of a watch. In the cases now under discussion either no torsion takes place during the return of the intestines, as in Huntington's case (fig. 10), or, much more rarely, reverse torsion takes place, as in Strehl's case (fig. 11). It is not improbable that the same conditions which make difficult the normal development of the jejunal coilsfrom the duodeno-jejunal loop also make difficult the normal return to the abdomen of the coils developed from the urnbilical loop.

We may, however, have an apparently normal development of the left colic loop and of the duodeno-jejunal loop and, nevertheless, have a return of the umbilical part of the intestines into the abdominal cavity without torsion. In a case of this kind, illustrated by Jaboulay, ${ }^{5}$ the colic loop and the abdominal coils of the jujunum appear to be essentially normal while the umbilical portion of the colon lies in the mid abdominal region with the caecum in front of the bladder and the umbilical coils of the small intestine (ileum) occupy the right side of the abdominal cavity.

Normally, after the caecum has passed from the umbilical cord into the right hypochondriac region, the proximal portion of the colon gradually becomes lengthened and bent toward the right iliac fossa and the caecum is thus brought to its adult position. Meanwhile a further rotation of the proximal part of the colon and of the ileum takes place so that the ileac coils come to life in front of the caecum and the ileum enters the caecum from the left side. The colic portion of the mesentery of the entero-colic loop becomes fused to the dorsal abdominal wall beginning where the superior mesenteric artery crosses the duodenum and extending toward the caecum. To the left of where the superior mesenteric artery crosses the duodenum the mesentery is fused to the ventral surface of the duodenum. At the left inferior margin of the area of fusion of the colic mesentery we have the line of origin of the free mesentery of the small intestines. The portion of the small

5 Province med., 1891, cited by Fredet in Poirier and Charpy, Traite d'anatomie humaine, T, 4, fig. 472. 
intestines attached through its mesentery to the duodenum we may look upon as belonging in the main to the primitive duodenojejunal loop of the small intestines; that portion attached to the left and below where the superior mesenteric artery crosses the duodenum we may look upon as belonging in the main to the umbilical coils of the intestines. The primitive relations of the mesentery of these two portions of the small intestines is shown in figure 7 . They undoubtedly vary, to some extent inversely, in development in different bodies. The duodeno-jejunal coils correspond in the main with the transverse coils in the adult, described by Henke, the umbilical coils to the vertical coils.

Exceptionally good illustrations of the attachment of the mesentery of the jejunum and ileum have been furnshed by Stopnitzki. ${ }^{6}$

He has pictured 'high forms' running nearly horizontally to the right from the base of the superior mesenteric artery; low forms bowing well to the left of the usual line of attachment and various intermediate forms. He shows the cut base of the mesentery to be widest in the region of the main trunk of the superior mesenteric artery and to taper off from here taward the colic extremity of the ileum and the jejunal end of the duodenum. He has divided the base of the mesentery into twenty parts and the intestinal margin into twenty parts and compared the distance between the corresponding segments. He found that, as a rule, the mesentery showed two regions of maximum width, one near the seventh to eighth and one near the sixteenth to seventeenth of the twenty segments, counting from the duodenal end. In only two out of every twenty-five cases was there a marked departure. In these two cases the mesentery was widest about the middle of the distance between the two extremities of the small intestine. To what extent the proximal and distal halves of the free small intestine, each with its mesentery longest toward the junction of the distal with the middle third, correspond with the parts of the intestine the coils of which originated respectively within the umbilical cord and within the abdominal cavity we have at present no data.

\footnotetext{
${ }^{6}$ Untersuchungen zur Anatomie des menschlichen Darmes, Internat. Monatschr. f. Anatomie u. Physiologie, Bd. 15, p. 219, 1898.
} 
The distribution of the branches of the superior mesenteric artery are, however, suggestive.

The branches of the superior mesenteric artery which supply the free small intestines may be divided into two sets, those which arise near and distal to the ileo-colic artery and those which arise proximal to this artery. The former branches in the adult, in the specimens I have examined, supply the distal two-thirds to three-fifths of the free small intestines, the former the proximal third to two-fifths. I have found the same thing true in a fetus $22.5 \mathrm{~cm}$. long. The territory suppied by the distal branches corresponds, therefore, very well with the ileum, that supplied by the proximal branches, with the jejunum. The relations of the two sets of branches to the mesentery and duodenum suggests that the former supply the umbilical coils of the intestine, the latter abdominal coils, but a definite proof of this is possible only with injected specimens of early fetuses and these we unfortunately lack. There is, however, good reason to believe that the primitive umbilical coils correspoond essentially with the ileum, the abdominal coils with the jejunum. If we take coils 2 and 3 of Mall to represent the jejunum and coils 4, 5 and 6, the ileum we find from the data given by Mall (table 1, footnotes) that the ileum is about four times as long as the jejunum during the period immediately preceding the return of the umbilical loop. As the return of this loop takes place the abdominal coils (jejunum) grow rapidly so that in the $40 \mathrm{~mm}$. fetus studied by me the ratio of ileum to jejunum is as 4:3. After the return of the umbilical coils the ileum grows relatively much faster according to Mall's data so that in a fetus $130 \mathrm{~mm}$. long it is over three times as long as the jejunum. In the latter part of fetal life the adult proportions appear to be reached.

That we are justified in assuming a primitive development of a considerable part of the small intestines within the abdominal cavity may, I think, be deduced from the following table showing the relative development in length of the small and large intestines as compared with the growth in length of the axial part of the body. The data are based chiefly on those furnished by Mall ('97). 
From table 1 it may be seen that in embryos between 3 and 17 $\mathrm{mm}$. in length the small intestines grow at about the same rate as the axis of the body while the large intestines grow more slowly.

TABLE 1

To show the grow'h in length of the intestines ${ }^{1}$ as compared with the growlh in length of the trunk ${ }^{2}$

\begin{tabular}{|c|c|c|c|c|c|c|}
\hline \multirow{2}{*}{$\begin{array}{l}\text { DEEIGANATION OF } \\
\text { SPECIMENS }\end{array}$} & \multicolumn{3}{|c|}{ LENGTH IN MM. } & \multicolumn{3}{|c|}{$\begin{array}{c}\text { PROPORTIONAI, LENGTH AT SUCCESSIVE } \\
\text { STAGES }\end{array}$} \\
\hline & Specimens ${ }^{2}$ & $\underset{\text { intestine }}{\text { Small }}$ & Colon & Specimens & $\begin{array}{c}\text { Small } \\
\text { intestine }\end{array}$ & Colon \\
\hline $\mathrm{II}^{3}$ & 3 & 1.7 & 1.5 & & & \\
\hline$I X^{3}$ & 17 & 9.1 & 3.7 & 1.0 .06 & & \\
\hline $\mathrm{X}^{3}$ & 24 & 19.0 & 7.0 & & & \\
\hline & & & & $\begin{array}{l}1: 1 \\
(1: 1.41)^{5}\end{array}$ & $\begin{array}{c}1: 1.78 \\
(1: 3.75)^{5}\end{array}$ & $\begin{array}{c}1: 1.14 \\
(1: 2.16)^{5}\end{array}$ \\
\hline $\mathrm{VI}^{3}$ & 24 & 33.9 & 8.0 & $1: 1.17$ & $1: 1.53$ & $1: 1$ \\
\hline $\mathrm{XLV} \mathrm{S}^{3}$ & 28 & 52.1 & 8.0 & $1: 1,14$ & $1: 183$ & $1: 1.75$ \\
\hline LXXIX & 32 & 95.0 & 14.0 & $1: 1.25$ & $1: 1.47$ & $1: 1.50$ \\
\hline $8^{4}$ & 40 & 140.0 & 21.0 & $1: 2$ & $1: 2.61$ & $1: 2.37$ \\
\hline XXXIV 3 & 80 & 366.0 & 50.0 & $1: 1.63$ & $1: 1.57^{8}$ & $1: 1.70$ \\
\hline $\mathrm{XLVIII}{ }^{3}$ & 130 & 574.0 & 86.0 & $1: 2.57$ & $1: 3.66$ & $1: 6.45$ \\
\hline Infant ${ }^{9} \ldots$ & 334 & $\begin{array}{l}2100.0 \\
5372.0^{10}\end{array}$ & $\begin{array}{r}555.0 \\
1500.0\end{array}$ & $1: 2.55$ & $1: 2.56$ & $1: 2.70$ \\
\hline
\end{tabular}

1 As measured on the border opposite the mesenteric attachment.

${ }^{2}$ Vertex-breach measurement in fetuses. Vertex coccygeal measurement after birth.

${ }^{3}$ After Mall. ${ }^{4} \mathrm{~W}$ isconsin collection. 5 Comparing Embryos $\mathrm{IX}$ and VI.

${ }^{6}$ Comparing fetuses XLv and 8; duodenum 3.6: 7.27, jejunum (coils 2 and 3) 8.8: 56.4 , ileum (coils 4,5 and 6 ) $39.7: 74.5$.

7 Comparing fetuses 8 and xxxiv; duodenum 7.27: 11, jcjunum (coils 2 and 3 ) $56.4: 89$, ileum (coils 4,5 and 6 ) $74.5: 266$.

8 Comparing fetuses Xxxiv and XLvxr ; duodenum $11: 22$, jejunum (coils 2 and 3) $89: 132$ ileum (coils 4, 5 and 6) 266: 420 .

${ }^{9}$ Average after Weinberg.
${ }^{11}$ After Mall, Anat. Anz., Bd. 16, 1899.

${ }^{10}$ A verage after Sernoff.

THE A MERTCAN JOURNAL OF ANATOMY, VOI. 16, NO. 4 
The relative rate of growth of body axis is somewhat less than that of the intestines in embryos between 17 and $24 \mathrm{~mm}$. or less. There then begins a relatively very rapid development of the coils of the small intestines within the umbilical cord. In one fetus of $24 \mathrm{~mm}$. these are nearly twice as long as in another (compare $\mathrm{x}$ and $v i$ in the table). The relatively more rapid growth of the small intestines continues in fetuses between 24 and $28 \mathrm{~mm}$. in length, while the rate of growth of the large intestines still continues to be about equal to that of the axis of the body. During the next stage, however, in fetuses between 28 and $40 \mathrm{~mm}$. in length the small intestines grow nearly twice and the large intestine over twice as fast as the axis of the body. As may be seen from footnote 6 of the table, during this period the duodenum and the jejunum (abdominal part of the small intestines, primitive loops 1 to 3 of Mall) grow much more rapidly than the ileum (umbilical coils, loops 4 to 6 of Mall). The relatively great growth in length of the large intestines is due to the development of the left colic loop. After the return of the umbilical coils into the abdominal cavity, in fetuses between 40 and $80 \mathrm{~mm}$. in length, both the large and small intestines grow somewhat more rapidly in length than the axis of the body, but the difference is far less marked than in the preceding period. The ileum (loops 4,5 and 6 of Mall) grows relatively much faster than the jejunum (loops 2 and 3 of Mall) according to the data furnished by Mall. From this time on, although there are undoubtedly great individual differences in the growth in length of the intestines, on an average there does not appear to be much difference in the growth in length of the intestines as compared with that of the axis of the body, with the exception of a great increase in the length of the large intestine toward the latter part of fetal life.

From table 1 it is clear that the period of relatively greatest intestinal development is that immediately preceding and accompanying the return of the umbilical loop into the abdominal cavity, the period when the fetus is growing from 20 to $50 \mathrm{~mm}$. in length. This is the critical period in the development of the intestines. Variations which occur later are of minor importance. 
PLATES 
PLAT'E 1

EXPLANATION OF FIGURES

1 and 2 Ventral and lateral views of a reconstruction of the stomach, small and large intestines, reetum, bursa omentalis and mesentery, of a human fetus $27 \mathrm{~mm}$. long (No. 6, Wisconsin Collection) 7 diameters.

3 and 4 Ventral and lateral views of a reconstruction of the stomach, small and large intestines, rectum, bursa omentalis and mesentery of a fetus $35 \mathrm{~mm}$. long (No. 8, Wisconsin Collection). Owing to an artefact the coils in the umbilical cord were so injured that an accurate reconstruction could not be made. In figure 3 this portion of the intestines is not shown. In figure 4 a sohematic reconstruction of this portion of the intestines is given. 7 diameters. 
C. R. BARDEEN
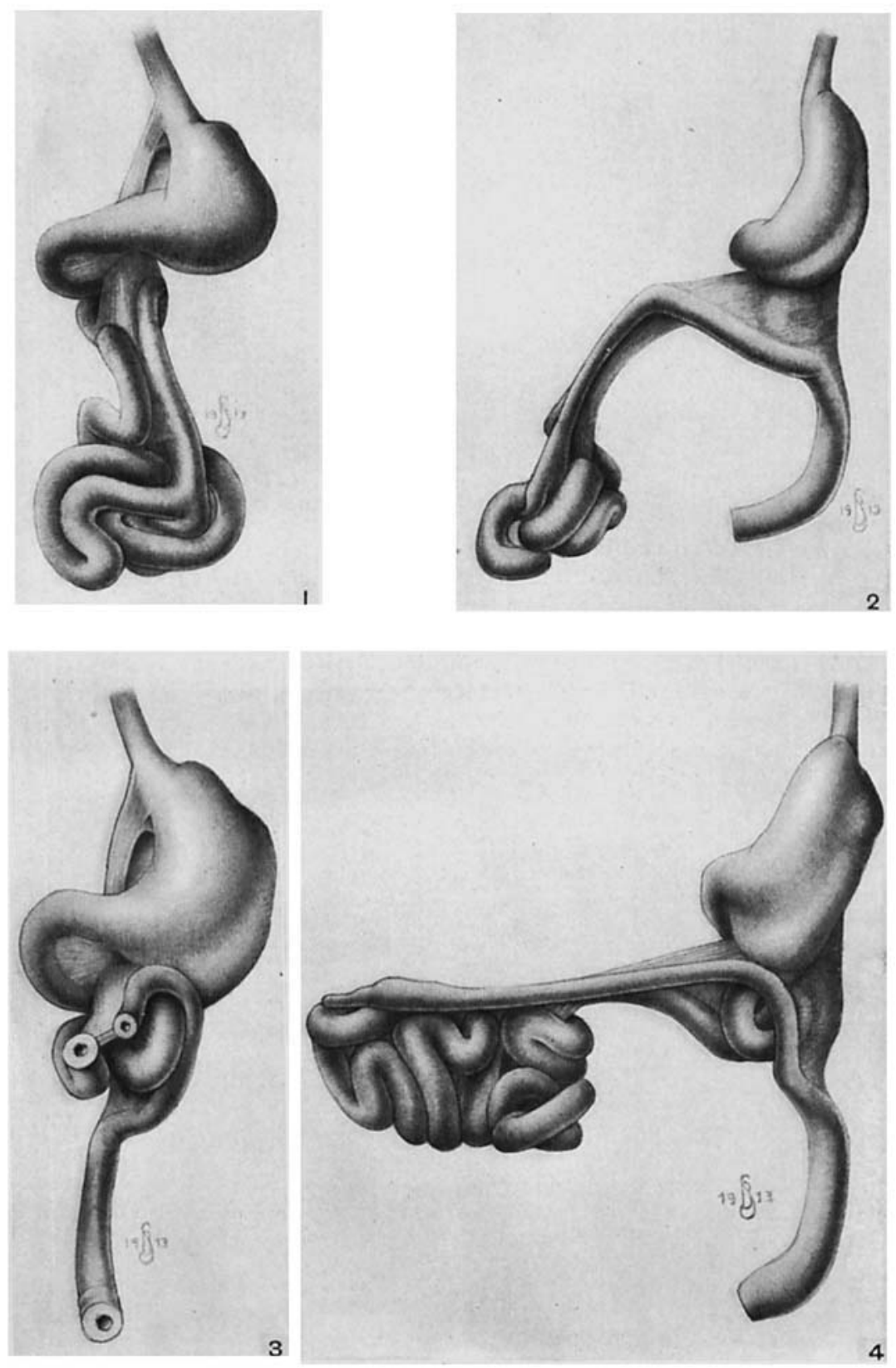
PLATE 2

EXPLANATION OF FIGURES

5 and 6 Ventral and lateral views of a reconstruction of the stomach, small and large intestines, bursa omentalis and mesentery of a fetus $40 \mathrm{~mm}$. Iong (No. 8 , Wisconsin Collection). In figure 6 the kidney and adrenal gland are also shown. 5 diameters.

7 Ventral view of a reconstruction of the stomach, duodenum, caecum, colon, rectum, bursa omentalis and mesentery of the same fetus. 5 diameters. The specimen here illustrated may be compared with that described by Mall (Supplementary note on the development of the human intestine; Anat. Anz., Bd. 16, pp. $5,492,1899)$. 
C. K. BARDEEN
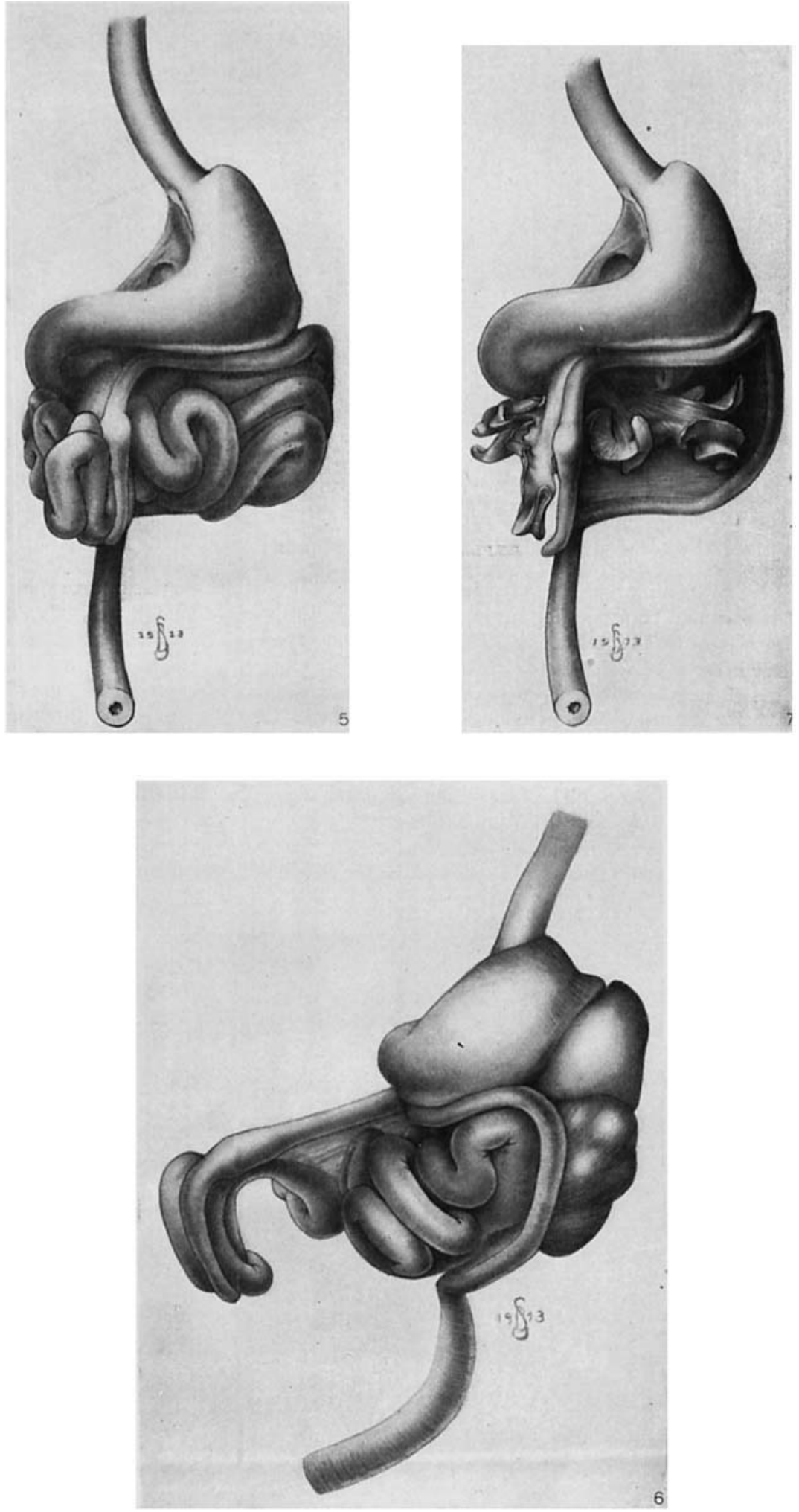


\section{PLATE 3}

\section{EXPLANATION OF FIGURES}

8 and 9 Views of the intestines in a subject in which there was a large splenic flexure and a transposition of the sigmoid colon to the right side of the body. In figure 9 the small intestines have been removed. The body in which the conditions here illustrated were found was that of a boy five and one-half years old who had died of chronic Bright's disease in an institution for the feeble-minded. No other marked abnormalities of development were noted. The position of the intestines is shown in the figures. The mesentery of the transverse mesocolon was short. The mesentery of the small intestines was attached to the body wall in essentially the normal position. The descending colon was in part fused to the left side of the mesentery of the small intestine. The great omentum extended downwards from the greater curvature of the stomach over the transverse colon and beneath the loop of the splenic flexure to the lower border of which it was attached. 
c. R. BAFDEEN
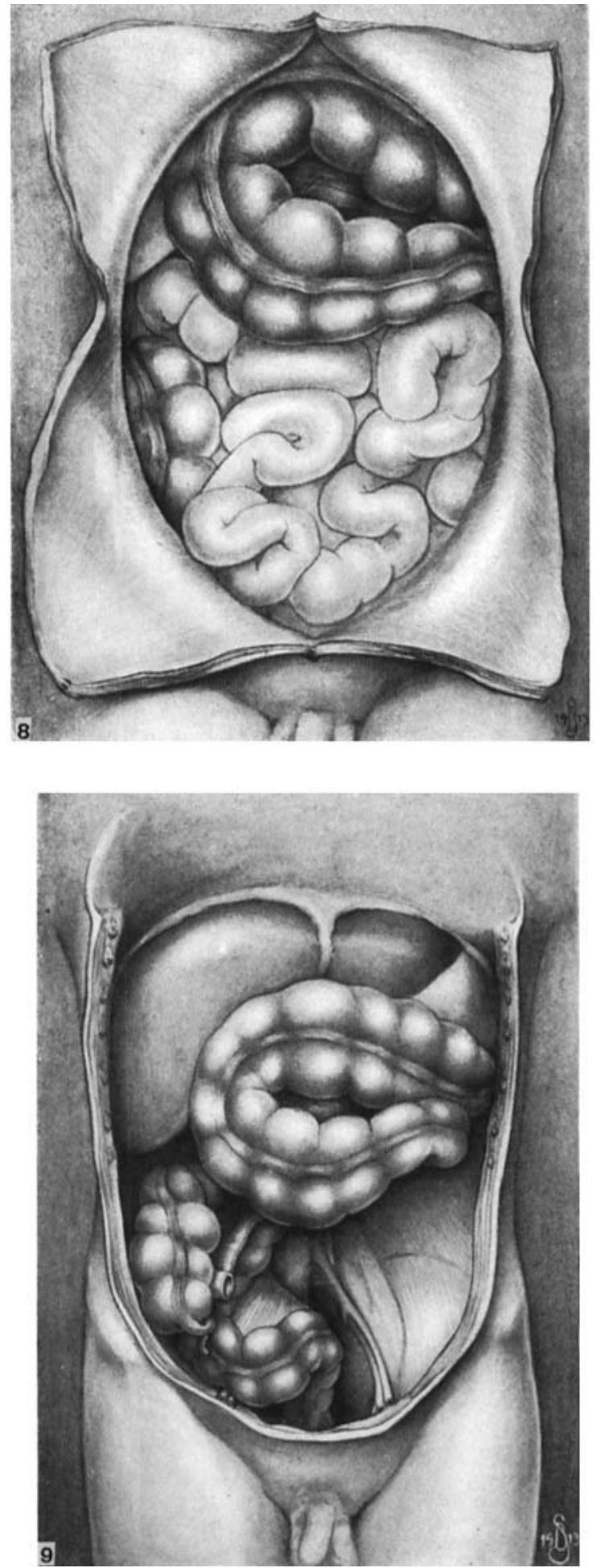
PLATE 4

EXPLANATION OF FIGURES

10 After Huntington, Anatomy of the peritoneum and abdomen, figure 121. To illustrate a case of good development of the left colic loop, arrested development of the duodeno-jejunal loop and non-rotation of the entero-colic loop.

11 After Strehl, Archiv f. klin. Chirurgie, Bd. 87, 1908, eited by Broman, Normale and abnorme Entwicklung des Menschen, figure 326. To illustrate a case of good development of the left colic loop, arrested development of the duodeno-jejunal loop and reverse rotation of the entero-colic loop. 

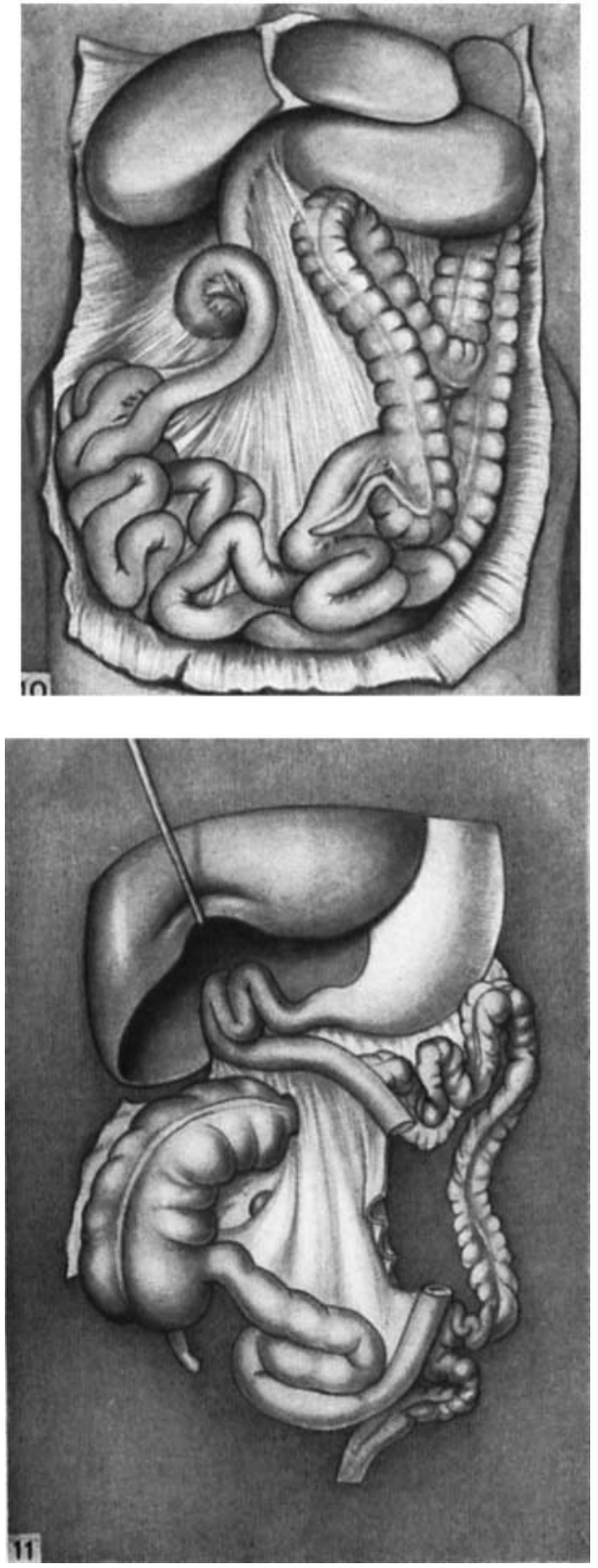